\title{
Electroplating and PVD Finishing Technologies in the Fashion Industry: Perspectives and Scenarios
}

\author{
Romeo Bandinelli *(D), Virginia Fani and Bianca Bindi
}

check for updates

Citation: Bandinelli, R.; Fani, V.; Bindi, B. Electroplating and PVD Finishing Technologies in the Fashion Industry: Perspectives and Scenarios. Sustainability 2021, 13, 4453. https:// doi.org/10.3390/su13084453

Academic Editors: Marcello Fera and Fabio Fruggiero

Received: 15 February 2021

Accepted: 14 April 2021

Published: 16 April 2021

Publisher's Note: MDPI stays neutral with regard to jurisdictional claims in published maps and institutional affiliations.

Copyright: (c) 2021 by the authors. Licensee MDPI, Basel, Switzerland. This article is an open access article distributed under the terms and conditions of the Creative Commons Attribution (CC BY) license (https:// creativecommons.org/licenses/by/ $4.0 /)$.
Department of Industrial Engineering, University of Florence, 50121 Firenze, Italy; virginia.fani@unifi.it (V.F.); bianca.bindi@unifi.it (B.B.)

* Correspondence: romeo.bandinelli@unifi.it

\begin{abstract}
This work deals with a comparison between electroplating and Physical Vapor Deposition (PVD) finishing technologies applied in the fashion industry, with a special focus on their environmental impacts. The goal of this work is to present and validate a Decision Support System (DSS) allowing companies to identify, through Life Cycle Assessment (LCA) analysis, which of the two types of finishing processes is more suitable in comparison with specific KPIs. After an investigation on the literature and an industrial background regarding the two technologies, the model and, in particular, the sequence of activities that were conducted, are presented. Since LCA is an articulated process, requiring specific and adequate skills that are often unavailable within companies operating in this specific sector, a tool that facilitates LCA execution is a requisite. This tool, though potential publicity will facilitate the adoption of these approaches and sustainability as a driver in the selection of different production process strategies.
\end{abstract}

Keywords: electroplating; PVD; fashion; LCA; sustainability

\section{Introduction}

Fashion is characterized by short lead times; low volumes; high volatility; low predictability; high impulse purchasing; and high variance, either in terms of different Stooking Keeping Units (SKUs) or in terms of color variety per SKU. Different varieties are realized by changing the colors of the raw material and components, rendering the finishing process a crucial aspect of the production process. As reported since the publication of [1], fashion products need to represent the mood of the moment and, consequently, the selling period is very short and seasonal, measured in months or even weeks. Demand for these products is rarely stable or linear, being influenced by external factors such as the weather, clientele, etc. Despite this, fashion represents one of the most important industries worldwide. Revenue in the fashion segment is projected to reach 143,526 million USD by the end of 2021, showing an annual growth rate of 5.30\% (CAGR 2021-2021), resulting in a projected market volume of 176,452 million USD by 2025.

Metal accessories play an important role within this industry, being responsible for the design and development of significant parts of final products, such as closures, buckles, rings, loops, and sails [2,3]. These items are produced with brass, zinc, or steel, covered with a thin layer of precious metal such as gold, ruthenium, palladium, etc. Traditionally, the finishing process of metal accessory companies is attained through electroplating technology, widely employed in countries where fashion industries are prominent, such as in Italy and France, while Physical Vapor Deposition (PVD), introduced more recently, plays a secondary role. Most of these factories are Small and Medium Enterprise (SME), with elevate skills in terms of technical aspects of the production process but with nonspecific competences on environmental aspects.

Although the solution for wastewater problems related to the electroplating industry have been analyzed in the literature [4-6], the increasing attention to sustainability issues calls for more environmentally friendly processes. Electroplating technology has recently 
been subject to investigation due to the high environmental impacts related to water pollution: electroplating wastewater contains highly toxic cyanide, cyanide complexes, and metal ions, making postproduction treatment a complex problem to be addressed by these companies $[7,8]$.

PVD technology better confronts these issues as water is not used. On the other hand, the lack of widespread competences in this technology in the fashion industry of European countries necessitates assigning production to eastern suppliers, mostly located in China. This leads to increases in lead time, which represents a critical success factor for the fashion industry itself.

This dichotomy makes the introduction of a Decision Support System (DSS) relevant in solving the tradeoff between environmental issues and service level. In harmony with this, the developed tool includes an LCA analysis on alternative electroplating and PVD finishing dies in order to determine the environmental effects of the two technologies. Moreover, the tool was developed in order to be easily adopted by SME companies with no specialized competence.

In order to validate the structure and the fundamental steps of the proposed analysis, interviews with practitioners working in fashion companies were conducted. During the case study, different software applications were used, from open source graphical tools for process mapping to Excel ${ }^{\mathrm{TM}}$, statistical software, and finally LCA software.

This paper is structured as follows. In Section 2, an industrial background is reported, where electroplating finishing and PVD are introduced. In Section 3, the proposed DSS is described, and in Section 4, the results are reported. Section 5 illustrates some conclusions and future steps.

\section{Industrial Background}

A finishing process is the final part of the metal accessory production process. Unlike in other sectors, this phase is crucial in the fashion industry because of the attention to color that has to be made by the companies. According to the critical success factors of luxury brands, quality issues are perceived as critical to the success of a product on the market. Most fashion companies have a full-time quality department [9] dedicated to these issues. Focusing on luxury, most small leather products (i.e., bags and shoes), most of them includes a metal accessory (i.e., a closure or a buckle), representing a significant feature of the final product. A specific color is defined, according to a specific pantone, and then produced by applying a thin film of precious metal over the metal accessory using electroplating or PVD technology. Whilst the electroplating technology is well known and adopted in the fashion industry, the introduction of PVD technology into the fashion industry is relatively recent or at least used to a lesser extent.

PVD technology [10-12] is a thin film deposition process in which the coating develops on the substrate. It involves the atomization or vaporization of a material from a solid source, usually called the target. In PVD processes, the material to be deposited (the target) is transformed into atomic particles using a physical thermal collision process and then directed onto the substrates in a gaseous environment under vacuum or low-pressure (plasma) conditions, where they then condense to form the coating layer. Typically, PVD processes are used to deposit films with thicknesses ranging from a few to a thousand nano-meters, and coatings can be deposited in conditions from room temperature up to $500{ }^{\circ} \mathrm{C}$ depending on the substrate plated and the specific application.

PVD technology is able to lay down layers that are more uniform with better fit than electroplating. The range of materials that can be coated is wider, and there are no harmful waste chemicals to dispose of.

The advantages of PVD technology can be summarized as follows: the multitude of substrate materials that can be coated (metals, alloys, ceramics, glass, and polymers), the essentially unlimited choice of deposited materials (metals, alloys, semiconductors, metal oxides, carbides, nitrides, and sulfides), the excellent adhesion of the deposited finish, and the simple adjustment of the microstructure by the choice of coating parameters. On the 
other hand, deposition rates are relatively low and technologically demanding processes are required to adjust the film thickness, which is complicated in the case of finishing geometrically complex components.

\subsection{PVD Pre- and Posttreatment}

A significant part of PVD technology is represented by pre- and posttreatment. Since few applications are found within the fashion industry, more ideas can be gathered from different sectors. Drag grinding is one of the most applicable [13], where the use of Titanium Nitride (TiN) with PVD technology is reported, starting from the first technological attempt in 1979 to the most recent applications. In that study, the production of TiN coating cutting tools with PVD is described and deeply analyzed, comparing different coatings such as TiAlN and AlTiN. An application of this techniques can be found in [14], where the effects of ultrasonic vibration-assisted milling were investigated in relation to the material surface integrity, tool wear, cutting forces, and fatigue resistance.

The effects of different input polishing parameters on the polishing efficiency and torque in the robotic polishing system for the circular-shaped workpieces (i.e., ring, cylinder, sphere, cone, etc.) have been studied in [15], where polishing force and tool speed are confirmed to be the most influencing parameters for polishing efficiency.

\subsection{Electroplating and PVD Environmental Impacts}

Regarding the environmental impacts, electroplating finishes (hard chrome, cadmium, and nickel in metal finishing) are currently recognized as a major source of environmental pollution in every country. In traditional sectors, wet bath technologies are being to be replaced with high-performance dry coating methods such as PVD, plasma-assisted chemical vapor deposition, and thermal spraying. Among these techniques, the achievements of PVD coatings in metal cutting and formation over the past 15 years show the most promising solution to the complicated situation where galvanic coatings seemed to be technologically and economically irreplaceable $[16,17]$. Regarding wastewater emissions related to the PVD process, the amounts of discharged substances can be neglegible, especially when compared to those generated by the electroplating process, can be considered negligible. However, even the PVD process is not totally waste-free. The volume of waste generated is dependent on factors such as the size and shape of the components, the machine load, the size of the coated area, and the cleanliness of the component [18].

In addition, electroplating has a major environmental impact, due to the continuous exposure of operators to substances potentially harmful to human health. This is corroborated by all the issues related to the use of cadmium and especially chromium, impacting on the social sustainability aspects [19].

\subsection{Electroplating and PVD Production Costs Comparison}

Compared to traditional electroplating technology, the PVD process is relatively more expensive due to the major demand required in the production process. As a consequence, electroplating is more popular among manufacturers of low-value items. As a general rule, PVD coatings have a higher cost and are used for small, high-unit-value items such as wear coatings on cutting tools. The performance of PVD coatings is higher, resulting in lower operating costs.

\section{The Proposed Model}

In the previous paragraph, the main finishing technologies used in the industry, namely electroplating, and PVD, were introduced. In this section, the model developed in order to support managers in the choice between those techniques is reported. The tool, with its limitations and characteristics, was implemented in a specific case study, where the final items compared are sails and chains, made of brass and steel.

As the first step in the analysis, the relative production chains were examined. The first production chain involved brass sails and chains, where finishing was performed with 
the galvanic process and cataphoresis coating. The second production chain involved steel sails and chains, with PVD finishing and coating.

\subsection{Supply Chain Processes Mapping and Analysis}

The production of metal accessories to be used in leather goods and clothing for the fashion sector represents a very important aspect of this industry. It is inhabited by companies that are often very different from each other, both in terms of size and operational structure. These companies range from small and family-run ones to very big businesses. Some companies are structured to produce metal accessories entirely in-house, as the latter are equipped with all the machinery and skills necessary to produce and finish the product, from the mechanical workshop to the galvanic or PVD finishing department. Others, instead, perform only some of the production phases internally and rely on external suppliers for the remaining operations. Again others, on the other hand, make use of an established supply chain for almost all of the phases of the entire production process. In turn, they personally perform very few of the phases, often only one phase, such as the final packaging.

The production chains related to the sails and chains differ among themselves both in terms of participants and of geographical areas involved. In particular, in the analysis carried out, the different supply chains are distinguished by two specific criteria:

- the different methods in raw material procurement and

- the different types of finishing processes.

In most cases, the raw sail is purchased from suppliers that produce them with the molding process. Regardless of the process of producing the blank, which is important for LCA purposes, the possible scenarios for brass or steel components are as follows:

- the sails and chains are purchased in Italy, with an average lead time of a 1 week;

- the sails and chains are purchased in China, with an average lead time of 3 weeks.

After that, a distinction must then be made based on what the components are made from (brass or steel). In the case of the brass components, the galvanic finishing process with cataphoresis coating is usually carried out in Italy, with an average lead time of 2 weeks. Regarding the steel components, the PVD finishing process has only recently been introduced in Italy, while in China, it has been widely used for a longer period of time. Two possible scenarios can be therefore classified:

- the PVD finishing process with coating carried out in Italy, with an average lead time of 2 weeks, using blanks purchased in either Italy or in China;

- the PVD finishing process with coating carried out in China, with an average lead time of 3 weeks, using blanks purchased in China. This usually requires the presence of an agent in China. The agent is then required manage the purchase of raw materials, to send them to Chinese companies for PVD finishing, and to finally ship the finished products to Italy.

\subsection{Model Definition}

As explained in the previous paragraph, the analysis tool is designed to be easily used by industrial users. The required input data include materials and energy consumption, and waste substances of the processes subjected to LCA analysis. Even if most of the parameters can be gathered starting from the configuration described in Section 3.1, some model parameters that are characteristic of the specific productive system cannot be defined in a univocal way and have to be defined by the users.

The Decision Support System (DSS) model, in fact, has been pre-filled by considering the most widespread metal accessory supply chains. However, some specific processes vary depending on the specific characteristics of the company (i.e., type of machine tools, capabilities of the employees, etc.).

The purpose of the DSS model is to identify, for a given production, the Break Even Point (BEP) between galvanic and PVD finishing technology dies in terms of environmental 
impact, i.e., the number of batches from which one of the two dies has a greater impact than the other.

Additional drivers (i.e., social aspects, production costs, and quality measurements) can be added to the model in order to compare the different choices. These choices can be compared, not only according to environmental indicators but also toward a more comprehensive objective function.

\subsection{The Conceptual Framework}

Through the following conceptual map in Figure 1, the principle steps in the construction of the analysis tool are reported.

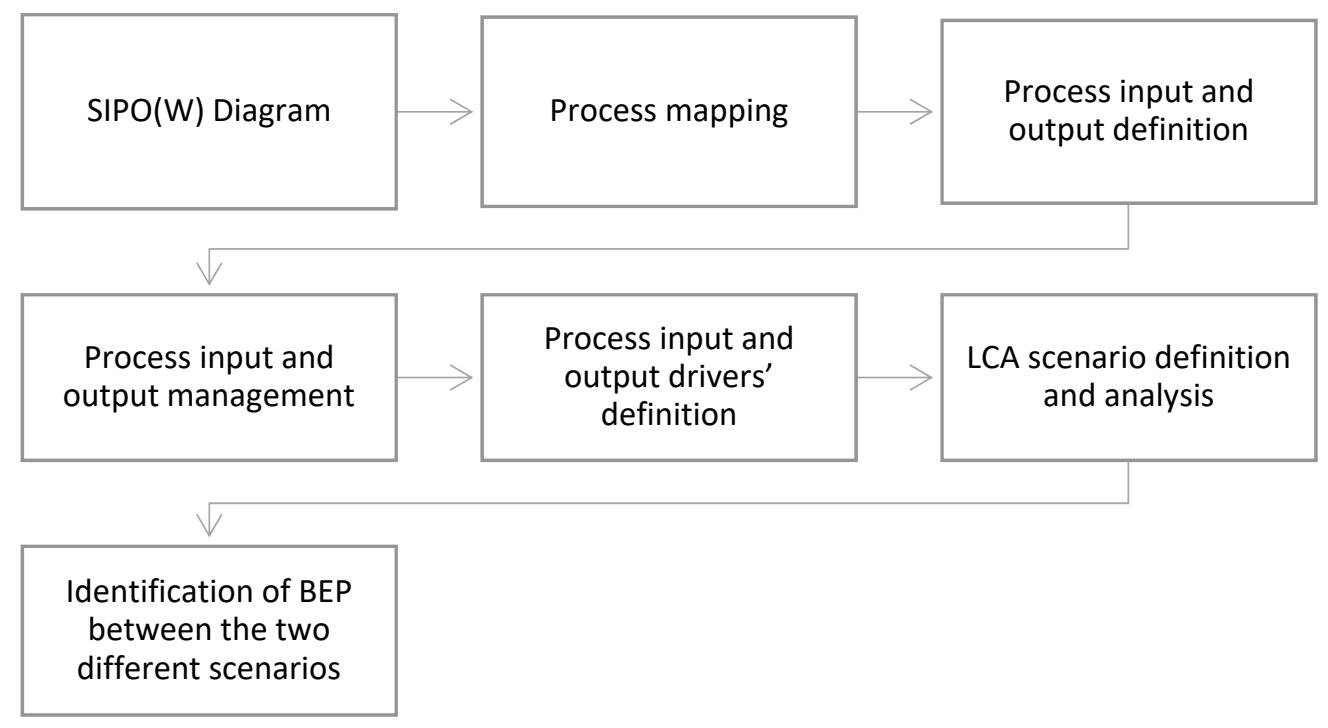

Figure 1. Conceptual framework of the proposed model.

These phases, demarcating the subdivisions in the developmental process of our model for the LCA analysis has been divided, will be described in more detail in the following paragraphs.

\section{4. $\operatorname{SIPO}(W) C$ Diagram}

In order to develop the proposed model, the Suppliers Inputs Process Outputs Customers (SIPOC) diagram was used. Starting from that, a modified version able to integrate the waste and waste substances generated by the process was defined. This is how our $\mathrm{SIPO}(\mathrm{W}) \mathrm{C}$ diagram was born (Table 1 ), where the additional $\mathrm{W}$ within the acronym stands for Waste. This was an important addition, given that the case study involves LCA analysis and is therefore linked to environmental impacts, of which waste substances generated by the process represent an important contributory factor. The SIPOC diagram is one of the most widely used tools in the area of process improvement and optimization. The diagram is a simple tool that provides a high-level overview of a product or process using a visual form with immediate impact. All the activities of a company can be viewed as processes, which take one or more inputs from suppliers to create outputs. These outputs may include a service or a product for the customers of the company. The graphical visualization of a SIPOC diagram easily shows the business process by identifying its key components such as suppliers, inputs, process, outputs, and customers. We, therefore, use this instrument in order to provide a clear and rapid initial vision of the productive chain that we analyze in the process of constructing the model. Hence, what is presented is the $\mathrm{SIPO}(\mathrm{W}) \mathrm{C}$ diagram of the production chain that takes a metal accessory to either a galvanic or a PVD finish. 
Table 1. SIPO $(\mathrm{W}) \mathrm{C}$ diagram.

\begin{tabular}{cccccc}
\hline Suppliers & Inputs & Process & Outputs & Waste & Customers \\
\hline Metal raw material & $\begin{array}{c}\text { Metal raw } \\
\text { materials }\end{array}$ & Raw realization & Raw items & Raw savage & $\begin{array}{c}\text { Metal accessories } \\
\text { companies }\end{array}$ \\
\hline Energy suppliers & Energy & Finishing process & Defected raw items & $\begin{array}{c}\text { Galvanic } \\
\text { finishing wastes }\end{array}$ & $\begin{array}{c}\text { Finishing } \\
\text { companies }\end{array}$ \\
\hline $\begin{array}{c}\text { Third Part } \\
\text { Logistics providers }\end{array}$ & Fuel & PVD process & Final Items & finishing wastes & PVD companies \\
\hline $\begin{array}{c}\text { Galvanic raw } \\
\text { material suppliers }\end{array}$ & $\begin{array}{c}\text { Galvanic raw } \\
\text { material }\end{array}$ & Packaging process & Fefected & & Brands \\
\hline $\begin{array}{c}\text { PDV Target } \\
\text { suppliers }\end{array}$ & PVD Target & & & \\
\hline $\begin{array}{c}\text { Packaging } \\
\text { suppliers }\end{array}$ & Packaging & & & \\
\hline
\end{tabular}

The idea was to introduce the diagram at the start of the analysis since it serves is an instrument in providing a clear and rapid depiction of the objective of analysis.

\subsection{Process Mapping}

After the SIPO(W)C diagram, the following phase involved mapping the processes characterizing the single chain (i.e., the finishing processes), namely, electroplating with cataphoresis coating, and PVD with coating. Within the production chains examined, it is the finishing processes that distinguish one chain from another. The other processes, such as procurement of the raw material, logistics, and packaging, do not require the same level of detail as the finishing processes. The impacts of the latter processes can be more rapidly calculated as they are more readily available in the literature and they are not processes that differentiate one supply chain from another. The final comparison between the various supply chains relative to the case study, involve the choice between the number of production lots that make a finishing process more convenient.

The objective of this phase is to map the finishing processes, for example, using the standard notation Business Process Model and Notation (BPMN), in order to highlight which are the phases from the beginning to the end.

$\mathrm{BPMN}$ is a graphical representation for specifying business processes in a business process model, originally developed by the Business Process Management Initiative (BPMI). The BPMN objective is to support business process management by providing a notation that is intuitive to business users yet able to represent complex process semantics. It was endorsed as ISO 19510 in 2013.

\subsection{Process Input and Output Definition}

After representing the finishing processes through BPMN mapping, the succession of the respective compositional phases that compose them becomes clear. For the next step, it is therefore important, as the next step, to define more precisely the system that will be the object of the LCA analysis as follows:

- the assignment of the boundaries of the system, i.e., the set of life cycle phases that are taken into consideration, and

- the determination of what is the functional unit of reference for the process. This includes the size against which all data entering and leaving the process in question are normalized, i.e., the inputs and outputs, as well as the results.

In this case study, as reported in Figure 2, "from gate to gate" was considered. It involves entry into the company until the product is put on the market. With respect to the complete life cycle, that is "from cradle to grave", in fact, the phase of extraction (where usually no information are given) is omitted. Moreover, additional phases such as 
assembly, retail, and use are not included, since their energy consumption can be considered negligible. Lastly, "end of life" will also not be analyzed, since it is impossible to predict how the disposal will be performed. Ultimately, therefore, the macro-phases to be taken into consideration for the LCA analysis are the production processes of the raw material, the logistics within the supply chain, and above all, the finishing processes with the final phase of packaging.

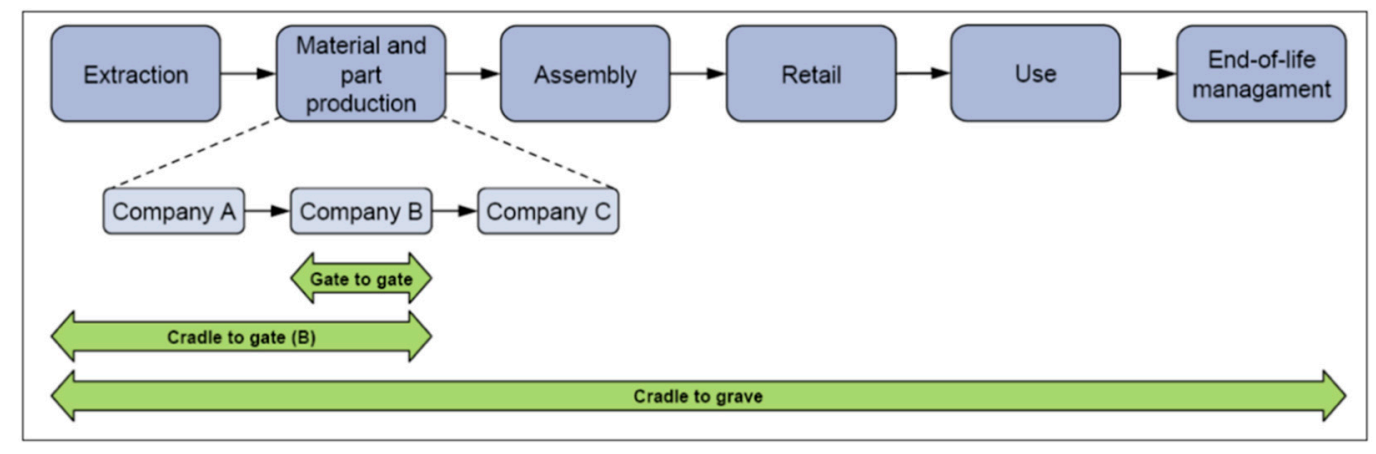

Figure 2. Cradle to grave vs. gate to gate.

Starting from the macro-phases identified in the previous section, it was necessary to identify the main processes shown in the $\operatorname{SIPO}(W) C$ diagram and, for each of these, to indicate their functional unit. In this specific case, for instance, the finishing processes are represented by the surface unit $\left(\mathrm{mm}^{2}\right)$ deposited by the galvanic and PVD processes. Instead, the processes involving raw material production and logistics are represented by kilograms of produced items.

After having identified the boundaries and the functional units of the system, the next step was to investigate which are the input and output elements of the phases of the complete finishing process (previously mapped) and useful for the LCA analysis. This process is mapped using a Multiple-Input and Multiple-Output (MIMO) approach. The inputs of the phases are represented mainly by the materials, energy, and substances used, respectively. Instead, the outputs of the single phases correspond instead to the various waste substances generated. At this point, the inputs and outputs of each phase are associated with the finishing processes that characterize the specific production supply chain.

\subsection{Process Input and Output Management}

Once the inputs and outputs of the individual stages of the finishing process are mapped, it is necessary to establish how the wastes generated by the processes are managed. In this phase, how each waste material from each phase will be stored and how it will then be recovered, must be specified. If the wastewater, once collected, is specifically stored and then processed, for example, through a dedicated recovery plant, it generates reduced impacts when compared to less environmentally friendly management and recovery processes.

For each hazardous waste substance, a Resource Conservation and Recovery Act (RCRA) is mapped according to that defined by the American agency Environmental Protection Agency (EPA). This regulation deals with the cataloguing of waste substances that are considered dangerous for the environment and establishes the correct management methods, that being, conservation and recovery.

Therefore, inputs and outputs of the electroplating finishing process are catalogued according to the guidelines reported by [20].

\subsection{Process Input and Output Drivers' Definition}

This phase identifies and quantifies the allocation drivers for both the inputs, i.e., energy and material consumption, and the outputs, i.e., the wastewater generated, of the process. In this phase, the user is asked to enter information in terms of material and energy 
consumption data and waste substances relative to the functional unit. From this, the total quantities relative to the single product are calculated.

This procedure must be carried out for each productive phase of the galvanic finishing and PVD processes, respectively, according to significant inputs and outputs for the purposes of the LCA analysis.

Therefore, data collection takes place phase by phase. Thereafter, the LCA software takes care of aggregating the consumption and waste of all of the production phases to determine the total quantities of the complete production process. This activity is very important for the determination of the final overall environmental impact associated with the process. It is also a phase that is closely linked to the nature and characteristics of the specific process. Moreover, it is a phase that must be carried out directly by the user, as it requires knowledge of the characteristics of the process to correctly identify total quantities. Various methodologies can be used to perform calculations of the total consumption and wastewater based on the specific characteristics of the individual production process.

\subsection{LCA Scenario Definition and Analysis}

Once all the information on the single product for all of the phases of the galvanic and PVD finishing processes (necessary to complete the analysis of an LCA software) were collected, respectively, the next step involves the development of the possible scenarios of consumption and waste substances corresponding to the various numbers of production lots. These scenarios are evaluated starting from the quantities related to the single product assuming a linear graduation scale.

The LCA software is, in fact, able to provide the impact related to a certain number of lots but is not able to directly calculate the impacts related to different numbers of lots that the user may wish to take into account.

This limitation has been overcome by carrying out collection and analysis of data relative to the material and energy consumption and of the total waste substances from the various phases of the finishing processes, corresponding to the various lot numbers. In detail, this activity is composed of two phases:

- data collection of material and energy consumption from the field and waste substances generated by the individual process phases, relative to various production lot dimensions, using an Excel sheet;

- $\quad$ analysis, using statistical software of the data collected in order to identify the function that approximates the trend of each consumption or wastewater substance as the number of batches.

This procedure makes it possible to identify the correlation between consumption and wastewater relative to batches of various size, starting from the same data relative to the single unit produced.

All data and information necessary for the LCA analysis, collected in the previous phases of our model, can then be inserted into specific LCA software. Then, the calculation of impacts related to all the production lot numbers for the specific impact categories can be performed. The environmental impacts can be calculated by dividing them for the specific impact categories upon which they act.

\subsection{Identification of BEP between the Two Different Scenarios}

In order to carry out an analysis in terms of BEP of these results, it is necessary to collect and analyze the output in a similar way to the one previously used to manage the input data of the LCA software. Therefore, the results, in terms of impacts shown in the previous paragraph, must be analyzed, using the statistical software. The objective is to identify which function best approximates the trend of emissions relating to the individual impact categories in relation to the number of productions lots.

At this point, the emissions for the individual impact category of the electroplating and PVD finishing processes can be reported on a single graph. This would permit the 
identification of the BEP in terms of the number of units produced and, therefore, which technology has less impact for that specific impact category.

In order to balance the LCA analysis, in terms of BEP, the impacts on the individual impact categories have to be summarized. This operation can be carried out starting from the results on the individual impact categories to identify an objective function for each finishing process through a weighted sum of these functions. The weights can then be personalized according to the specific company needs, to provide more importance to some impact categories over others. In order to carry out this operation correctly, the results of each impact category have to be normalized in order to avoid the impacts with the highest values being designated more important.

\section{Results}

Starting from a comparison between galvanic and PVD finishing technologies and the LCA analysis methodology, we developed a tool able to quantify the environmental impact of different metal accessory supply chains. This tool permits us to conduct an LCA analysis focused on the comparison between galvanic and PVD finishing processes, easy to comprehend even for companies that do not have the related in-depth knowledge. Providing these companies possess the available information on material and energy consumption as well as on production waste, this tool can be used. Hence, in using this tool these companies can evaluate different scenarios and can define the finishing technology that performs better in terms of environmental sustainability given a certain value of parameters such as the production batch size or the BEP. Moreover, the proposed tool overcomes one of the main limitations of LCA software, which is not being able to include lot sizing into the results. Essentially, the collection and analysis of results permitted for the definition of a function able to compare different results obtained with different lots sizes. In turn, this permitted the tool to calculate the impacts of batch sizes starting from the impact of the single product.

\subsection{Value of the Research}

The relevance of the proposed decision support model certainly lies in its originality. Evidence, from the research and interviews conducted, shows that nothing similar exists. In particular, unlike the long-used galvanic technology, PVD has only recently been introduced in the finishing process for fashion metal accessories and consequently the analysis and research on related production processes are still in their infancy. This aspect is even more relevant if we try to imagine all the possible future developments and implications that could be achieved starting from this calculation model. Moreover, it is especially important if we consider the fact that this tool renders the execution of an LCA analysis possible also for companies that do not have specific skills in the field but have the required data available. The model represents an important value facet of our research because most of the companies operating in this sector are not aware of LCA and the possible advantages of its application. Additionally, they do not usually have skilled staff able to carry out this type of investigation. The tool is designed, first of all, to provide an estimate of the environmental sustainability of the analyzed technologies through LCA analysis and to quantify energy and material consumption and emissions for production processes. In addition to the calculation of the BEP, as shown in our case study, the provided environmental impact can be used in multiple setup. We believe that the developed calculation model has a high practical industrial importance, especially due to the increasing attention given to environmental and social sustainability issues in production processes. Moreover, it is essential in the case study, involving processes emitting a high level of pollution are dangerous both for the environment and the workers involved.

\subsection{Boundaries of the Study}

The purpose of this study is to create a calculation model that can be useful in supporting operational and tactical decisions regarding the comparison between galvanic 
and PVD finishing technologies. In fact, it allows us to understand which of them is the most convenient in terms of environmental sustainability when changing the production lot sizes.

However, it is clear that the final choice between the two finishing technologies can be influenced by many heterogeneous factors, heterogeneous, far removed from the environmental theme, which cannot be taken into account only by an LCA analysis. For instance, some parameters usually deemed critical for the final decision in the most convenient finishing technology are the related costs and cost-effective performance, such as the required mechanical properties and the desired color.

\section{Conclusions and Further Research}

As mentioned in the previous paragraph, possible future developments are plentiful. First of all, the novelty of the tool. Secondly, its contribution to possible improvements in other decision-making issues alongside environmental sustainability. The most interesting future developments could involve: (i) The use of this model to analyze different types of productions, which involves very limited quantities per item and different raw material processing procedures to be investigated. This would enable us to understand if using numerical control machines is better than molding in the case of small lots instead of production in larger quantities; (ii) The exploitation of the results in terms of environmental impacts for purposes that are different from calculating the production BEP between two alternative processes; and (iii) The assessment of environmental impacts, the evaluation of economic sustainability through an analysis of production costs related to the two compared finishing technologies in order to identify the BEP and possible pricing strategies.

Author Contributions: The following statements should be used "Conceptualization, R.B. and V.F.; methodology, B.B.; software, V.F.; validation; writing—review and editing, B.B.; supervision, R.B. All authors have read and agreed to the published version of the manuscript.

Funding: This research received no external funding.

Institutional Review Board Statement: Not applicable.

Informed Consent Statement: Not applicable.

Data Availability Statement: Not applicable.

Conflicts of Interest: The authors declare no conflict of interest.

\section{References}

1. Christopher, M.; Lowson, R.; Peck, H. Creating agile Supply Chains in the Fashion Industry. Int. J. Retail Distrib. Manag. 2004, 32, 367-376. [CrossRef]

2. Fani, V.; Bandinelli, R.; Rinaldi, R. Toward a scheduling model for the metal accessories' suppliers for the fashion industry. In Proceedings of the Summer School Francesco Turco, Naples, Italy, 13-15 September 2016; pp. 166-170.

3. Fani, V.; Bandinelli, R.; Rinaldi, R. A simulation optimization tool for the metal accessory suppliers in the fashion industry: A case study. In Proceedings of the 31st European Conference on Modelling and Simulation, ECMS 2017, Budapest, Hungary, $23-26$ May 2017; pp. 240-246.

4. Upadhyay, K. Solution for wastewater problem related to electroplating industry: An overview. J. Ind. Pollut. Control 2006, 22, 59-66.

5. Belova, L.; Vialkova, E.; Glushchenko, E.; Burdeev, V.; Parfenov, Y. Treatment of electroplating wastewaters. E3S Web Conf. 2020, 203, 03009. [CrossRef]

6. Azmi, A.A.; Jai, J.; Zamanhuri, N.A.; Yahya, A. Precious Metals Recovery from Electroplating Wastewater: A Review. IOP Conf. Series: Mater. Sci. Eng. 2018, 358, 012024. [CrossRef]

7. Samuel, Z.A.; Workneh, T.S.; Trois, C.; Feyess, F.F. Challenges of wastewater discharge and techniques for treatment: A review. In Proceedings of the International Conference on Industrial Engineering and Operations Management, Kuala Lumpur, Malaysia, 8-10 March 2016; p. 2735.

8. Ramesh, B.; Bhanu, S.U.; Seeni, K. Waste Minimization in Electroplating Industries: A Review. J. Environ. Sci. Health Part C Environ. Carcinog. Ecotoxicol. Rev. 2009, 27, 155.

9. Brun, A.; Moretto, A. Organisation and supply chain for quality control in luxury companies. J. Fash. Mark. Manag. Int. J. 2013, 18, 206-230. [CrossRef] 
10. Mubarak, A.M.A.; Hamzah, E.H.E.; Tofr, M.T.M. Review of Physical Vapor Deposition (PVD) Techniques for Hard Coating. J. Mek. 2005, 20, 42-51.

11. Schlesinger, M.; Paunovic, M. Modern Electroplating; John Wiley and Sons Inc.: Hoboken, NJ, USA, 2010; ISBN 978-0-470-16778-6.

12. Singleton, R.; Singleton, E. Fundamentals of Barrel Plating. Metal Finish. 2011, 109, 14-22. [CrossRef]

13. Rodríguez-Barrero, S.; Fernández-Larrinoa, J.; Azkona, I.; López de Lacalle, L.N.; Polvorosa, R. Enhanced Performance of Nanostructured Coatings for Drilling by Droplet Elimination. Mater. Manuf. Process. 2016, 31, 593-602. [CrossRef]

14. Suárez, A.; Veiga, F.; Lacalle, L.; Polvorosa, R.; Lutze, S.; Wretland, A. Effects of Ultrasonics-Assisted Face Milling on Surface Integrity and Fatigue Life of Ni-Alloy 718. J. Mater. Eng. Perform. 2016, 25, 5076-5086. [CrossRef]

15. Mohsin, I.; He, K.; Li, Z.; Zhang, F.; Du, R. Optimization of the Polishing Efficiency and Torque by Using Taguchi Method and ANOVA in Robotic Polishing. Appl. Sci. 2020, 10, 824. [CrossRef]

16. Xiao, J.; Huang, Y.L. Technology Integration for Sustainable manufacturing: An Applied Study on Integrated Profitable Pollution Prevention in Surface Finishing System. Ind. Eng. Chem. Res. 2012, 51, 11434-11444. [CrossRef]

17. Baptista, A.; Silva, F.J.G.; Porteiro, J.; Míguez, J.L.; Pinto, G.; Fernandes, L. On the Physical Vapour Deposition (PVD): Evolution of Magnetron Sputtering Processes for Industrial Applications. Procedia Manuf. 2018, 17, 746-757. [CrossRef]

18. Sousa, V.F.C.; Silva, F.J.G. Recent advances on coated milling tool technology-a comprehensive review. Coatings 2020, 10, 235. [CrossRef]

19. Miśkiewicz, P.; Frydrych, I.; Cichocka, A. Application of Physical Vapor Deposition in Textile Industry. Autex Res. J. 2020, (in press). [CrossRef]

20. Palmer, S.A.K.; Breton, M.A.; Nunno, T.J.; Sullivan, D.M.; Surprenant, N.F. Metal/Cyanide Containing Waste Treatment Technologies, Chemie Ingeneur Technik. Noyes Data Corp. 1988, XIV, 721S. [CrossRef] 